\title{
Assessment Stability and Informative of Diagnostic Matrix in Analysis States of Reinforced Concrete Slab
}

\author{
Vladimir Sokolov ${ }^{1}$, Tatiana Musorina ${ }^{1,{ }^{*}}$, Ekaterina Starshinova ${ }^{1}$ and Ivanna Popovych $^{2}$ \\ ${ }^{1}$ Peter the Great St. Petersburg Polytechnic University, 195251 Polytechnicheskaya 29, St.Petersburg, \\ Russia \\ ${ }^{1}$ National Aviation University, 03058 Kosmonavta Komarova, 1, Kyiv, Ukraine
}

\begin{abstract}
In this article was examined the issues of sustainability and informative of diagnostic matrix, which are used when it is necessary to determinate the technical condition of constructions. Determination based on the mathematical instrument of technical diagnostics. One of the most widespread methods of technical diagnostics - a statistical method of Bayes is used.
\end{abstract}

\section{Introduction}

To solve tasks of technical condition definition of building constructive elements, offered an approach, based on the use of probabilistic mathematical instrument of technical diagnostics. Diagnosis is performed using probabilistic methods states recognition of complex technical systems. Calculations of probabilistic parameters are executed with use of the statistical method of Bayes, most widespread in technical diagnostics [3].

Bayes's method provides collecting statistical information on diagnostic results over last years. These results have formed the content of diagnostic matrices. One of the most important tasks is to assess the stability of these matrices, that is make influence on changes of statistical information results of calculation by Bayes's formula[1].

In article [2], the solution of this problem is based on theoretical instrument of information theory. Estimated weight of diagnostic features and diagnostic value as a whole. It was shown that the exclusion of little information statistics from diagnostic matrix provides quantitative change distribution of state probabilities, however have not provide any qualitative changes of the results. Moreover, the result has been updated in the sense of being more certainty (entropy - degree of uncertainty - has decreased by 1.5 times).

Nowadays, in normative base not defined quantitative reduction bearing abilities of building structures. This situation is typical when using classification of technical state of building objects, both, their defects and damage, and using the classification of the technical conditions[4]. Quality of construction object state eventually decreases in comparison with the technical state put at design and during the construction. In $[8,9]$ rightly pointed out that the safe operation of buildings requires a constant examination of its

* Corresponding author: flamingo-93@mail.ru 
technical condition, and science-based appointment of the relevant categories for its construction elements.

In this paper, the research of sustainability and informative diagnostic matrix is based on multivariate numerical experiment. Considered diagnostic matrix composed for concrete beams of reinforced concrete slab. The matrix consists of 9 signs, 5 of which are simple (answer the question "yes" or "no"), and 4 more complex (with bits and intervals).

The issues involved in assessing the technical condition of a number of authors. In these papers the assessment of technical conditions determined on the basis of: the theory of risk and structural safety [16], the logical-probabilistic approach [17], based on a combination of probabilistic and possibility approaches [18], based on the application of the theory of fuzzy sets $[19,20]$ and etc.

In [2] these paper the technical condition of the main and secondary beams and of plate sections and columns. The degree of certainty of the overall system is determined by taking into account the impact of each component, so that the technical condition of the system elements can either improve or become worse.

In [3] these paper calculating posterior probabilities of states for each element, carried out an analysis of the results obtained using the apparatus of probability theory and using the concept of information entropy. On this basis, constructed a multi-level model of diagnosis. This approach to the assessment of the technical condition of the building is offered for the first time.

In [4] on the basis of great theoretical and practical experience in the construction of a special purpose the authors suggest the possibility of monitoring the bearing elements of the building objects when exposed to static and dynamic loads. It is proposed to use an integrated method of diagnosing the state of construction projects under dynamic loading. The method is based on the search for diagnostic features reduce the carrying capacity of structure sand sub grade in the transfer function of the object model of the famous "black box."

These paper [5] is devoted to ensuring safe operation of buildings, which is determined by a complex of factors that depend on: the design decisions and their implementation during construction, the residual resources and the technical state of the object, the degree of change of object and environmental standards for the operation and the quality of their compliance during the lifetime of the object, and so on. Safety of operation it is not only technical, but also an economic problem, since the totality of the costs of reproductive events during the lifetime of the object is comparable to the cost of new construction, and often exceed them.

Operation phase is the most prolonged period of operation of the facility, so planning costs, and site restoration should be based on learning and forecasting of the technical condition of the building and its components, taking place over time, to determine the composition and scope of work.

Purpose of the research: Determine the information stability of the diagnostic matrix. Assess the degree of change between "input" priori statistical information and "output", which was estimated. For this it is necessary to solve the following tasks:

1. Analyze various options of signs realization by their exception one by one.

2. Assess how thus exceptions change the probabilistic parameters of states, which considered element of the system - the main beams, will take.

\section{Materials and Methods}

As noted above, this article study sustainability and informative of diagnostic matrix based on multivariate quantitative experiment. Quantitative experiment consisted of performing a large number of calculations, which was taken by using software PATC (Probabilistic 
Analysis of Technical Condition) [2]. Software PATC based on the most widespread statistical method of Bayes. The method consists in the fact that if there is a state Si and simple sign kj, occurring in this state, then the probability of co-occurrence of events (the availability of the system state $\mathrm{Si}$ and feature $\mathrm{kj}$ ) in accordance with the concepts of probability theory, will be obtained by the following Bayes's formula:

$$
P\left(S_{i} / k_{j}\right)=P\left(S_{i}\right) \frac{P\left(k_{j} / S_{i}\right)}{P\left(k_{j}\right)} .
$$

For a complex of signs:

$$
P\left(S_{i} / K^{*}\right)=\frac{P\left(S_{i}\right) P\left(K^{*} / S_{i}\right)}{\sum_{s=1}^{n} P\left(S_{s}\right) P\left(K^{*} / S_{s}\right)} .
$$

where $P\left(S_{i} / K^{*}\right)$ - probability of the diagnosis of $S_{i}$ after results of diagnostics with a complex of signs were obtained.

The analysis carried out for reinforced concrete floor beams, diagnostic matrix has the form shown in Table 1. Thus, the table is based on preparatory statistical data, which means it includes priori probabilities of the states and features. The decision depends on rule that an object with a complex of features $K^{*}$ refers to a state of $S_{i}$, if the posterior probability of this state $P\left(S_{i} / K^{*}\right)$ is the largest of all.

\begin{tabular}{|c|c|c|c|c|c|c|c|c|c|}
\hline \multirow{3}{*}{ № } & \multirow{3}{*}{$\begin{array}{l}\text { Diagnostic } \\
\text { features }\end{array}$} & \multirow{3}{*}{ kij } & \multirow{3}{*}{ 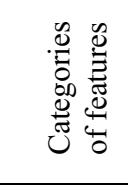 } & \multirow{3}{*}{$\mathrm{p}(\mathrm{kij})$} & $\begin{array}{l}\text { State } \\
\text { S1 }\end{array}$ & $\begin{array}{l}\text { State } \\
\text { S2 }\end{array}$ & $\begin{array}{l}\text { State } \\
\text { S3 }\end{array}$ & $\begin{array}{l}\text { State } \\
\text { S4 }\end{array}$ & $\begin{array}{l}\text { State } \\
\text { S5 }\end{array}$ \\
\hline & & & & & $\mathrm{P}(\mathrm{S} 1)$ & $\mathrm{P}(\mathrm{S} 2)$ & $\mathrm{P}(\mathrm{S} 3)$ & $\mathrm{P}(\mathrm{S} 4)$ & $\mathrm{P}$ (S5) \\
\hline & & & & & 0.18 & 0.29 & 0.35 & 0.13 & 0.05 \\
\hline \multirow{2}{*}{1} & \multirow{2}{*}{$\begin{array}{c}\text { Damages of } \\
\text { external } \\
\text { surface }\end{array}$} & k11 & yes & $\mathrm{p}(\mathrm{k} 11)$ & 0.11 & 0.17 & 0.29 & 0.54 & 0.80 \\
\hline & & $\mathrm{k} 12$ & no & $\mathrm{p}(\mathrm{k} 12)$ & 0.89 & 0.83 & 0.71 & 0.46 & 0.20 \\
\hline \multirow{2}{*}{2} & \multirow{2}{*}{$\begin{array}{l}\text { Longitudinal } \\
\text { cracks in } \\
\text { protective } \\
\text { layer }\end{array}$} & $\mathrm{k} 21$ & yes & $\mathrm{p}(\mathrm{k} 21)$ & 0.06 & 0.14 & 0.23 & 0.77 & 0.60 \\
\hline & & $\mathrm{k} 22$ & no & $\mathrm{p}(\mathrm{k} 22)$ & 0.94 & 0.86 & 0.77 & 0.23 & 0.40 \\
\hline \multirow{3}{*}{3} & \multirow{3}{*}{$\begin{array}{c}\text { Normal } \\
\text { cracks(width } \\
\text { of opening) }\end{array}$} & $\mathrm{k} 31$ & $\begin{array}{l}<0.4 \\
\mathrm{~mm}\end{array}$ & $\mathrm{p}(\mathrm{k} 31)$ & 0.76 & 0.59 & 0.40 & 0.15 & 0.20 \\
\hline & & $\mathrm{k} 32$ & $\begin{array}{c}\text { до } 1.0 \\
\text { mm }\end{array}$ & $\mathrm{p}(\mathrm{k} 32)$ & 0.18 & 0.34 & 0.43 & 0.62 & 0.40 \\
\hline & & $\mathrm{k} 33$ & $\begin{array}{l}\geq 1.0 \\
\mathrm{~mm}\end{array}$ & $\mathrm{p}(\mathrm{k} 33)$ & 0.06 & 0.07 & 0.17 & 0.23 & 0.40 \\
\hline \multirow{3}{*}{4} & \multirow{2}{*}{$\begin{array}{l}\text { Inclined } \\
\text { cracks }\end{array}$} & k41 & yes & $\mathrm{p}(\mathrm{k} 41)$ & 0.06 & 0.17 & 0.34 & 0.31 & 0.20 \\
\hline & & $\mathrm{k} 42$ & no & $\mathrm{p}(\mathrm{k} 42)$ & 0.94 & 0.83 & 0.66 & 0.69 & 0.80 \\
\hline & & $\mathrm{k} 51$ & $\begin{array}{l}\text { design } \\
\text { strength }\end{array}$ & $\mathrm{p}(\mathrm{k} 51)$ & 0.72 & 0.48 & 0.49 & 0.15 & 0.20 \\
\hline
\end{tabular}

Table 1. Diagnostic matrix for the main beams of the monolithic ferroconcrete overlap. 


\section{TPACEE-2016}

\begin{tabular}{|c|c|c|c|c|c|c|c|c|c|}
\hline \multirow[t]{2}{*}{5} & \multirow[t]{2}{*}{$\begin{array}{l}\text { Strength of } \\
\text { concrete }\end{array}$} & $\mathrm{k} 52$ & $\leq 30 \%$ & $\mathrm{p}(\mathrm{k} 52)$ & 0.22 & 0.31 & 0.20 & 0.39 & 0.20 \\
\hline & & k53 & $>30 \%$ & $\mathrm{p}(\mathrm{k} 53)$ & 0.06 & 0.21 & 0.31 & 0.46 & 0.60 \\
\hline \multirow{3}{*}{6} & \multirow{3}{*}{$\begin{array}{c}\text { Corrosion of } \\
\text { armature }\end{array}$} & k61 & $<5 \%$ & $\mathrm{p}(\mathrm{k} 61)$ & 0.76 & 0.59 & 0.29 & 0.15 & 0.20 \\
\hline & & $\mathrm{k} 62$ & $5-20$ & $\mathrm{p}(\mathrm{k} 62)$ & 0.18 & 0.24 & 0.37 & 0.39 & 0.20 \\
\hline & & k63 & $>20 \%$ & $\mathrm{p}(\mathrm{k} 63)$ & 0.06 & 0.17 & 0.34 & 0.46 & 0.60 \\
\hline \multirow{3}{*}{7} & \multirow{3}{*}{ Deflection } & k71 & limit & $\mathrm{p}(\mathrm{k} 71)$ & 0.83 & 0.48 & 0.51 & 0.31 & 0.20 \\
\hline & & $\mathrm{k} 72$ & $\leq 30 \%$ & $\mathrm{p}(\mathrm{k} 72)$ & 0.11 & 0.38 & 0.23 & 0.46 & 0.20 \\
\hline & & $\mathrm{k} 73$ & $>30 \%$ & $\mathrm{p}(\mathrm{k} 73)$ & 0.06 & 0.14 & 0.26 & 0.23 & 0.60 \\
\hline \multirow{2}{*}{8} & \multirow{2}{*}{$\begin{array}{c}\text { Strength } \\
\text { condition on } \\
\text { normal cross- } \\
\text { section }\end{array}$} & k81 & satisfied & $\mathrm{p}(\mathrm{k} 81)$ & 0.94 & 0.90 & 0.86 & 0.69 & 0.20 \\
\hline & & $\mathrm{k} 82$ & no & $\mathrm{p}(\mathrm{k} 82)$ & 0.06 & 0.10 & 0.14 & 0.31 & 0.80 \\
\hline \multirow{2}{*}{9} & \multirow{2}{*}{$\begin{array}{l}\text { Strength } \\
\text { condition on } \\
\text { inclined } \\
\text { sections }\end{array}$} & k91 & satisfied & $\mathrm{p}(\mathrm{k} 91)$ & 0.94 & 0.83 & 0.60 & 0.61 & 0.20 \\
\hline & & k92 & no & $\mathrm{p}(\mathrm{k} 92)$ & 0.06 & 0.17 & 0.40 & 0.39 & 0.80 \\
\hline
\end{tabular}

Realizations of signs for $G_{l}$ (for example) beam (as an example they are highlighted in Table 1 by yellow color):

1. there are damages of external surface;

2. there are longitudinal cracks in protective layer;

3. there are normal cracks with width of opening more than $1 \mathrm{~mm}$;

4. there are inclined cracks;

5. strength of concrete is lower than the design strength by $30 \%$;

6. corrosion of naked armature is more than $20 \%$;

7. deflection exceeds limit by more than $30 \%$;

8. strength condition according the calculation by normal cross-section is not satisfied;

9. strength condition according the calculation by inclined sections is not satisfied.

When using data of table 1 , a technique offered above and the specified conditions following values were received:

$$
\begin{aligned}
& P\left(S_{1}\right) P\left(K^{*} / S_{1}\right)=0.18(0.11 \cdot 0.06 \cdot 0.06 \cdot 0.06 \cdot 0.06 \cdot 0.06 \cdot 0.06 \cdot 0.06 \cdot 0.06 \cdot 0.06)=0 \\
& P\left(S_{2}\right) P\left(K^{*} / S_{2}\right)=0.29(0.17 \cdot 0.14 \cdot 0.07 \cdot 0.17 \cdot 0.21 \cdot 0.17 \cdot 0.14 \cdot 0.10 \cdot 0.17)=0 \\
& P\left(S_{3}\right) P\left(K^{*} / S_{3}\right)=0.35(0.29 \cdot 0.23 \cdot 0.17 \cdot 0.34 \cdot 0.31 \cdot 0.34 \cdot 0.26 \cdot 0.14 \cdot 0.40)=0.02 \cdot 10^{-5} \\
& P\left(S_{4}\right) P\left(K^{*} / S_{4}\right)=0.13(0.54 \cdot 0.77 \cdot 0.23 \cdot 0.31 \cdot 0.46 \cdot 0.46 \cdot 0.23 \cdot 0.31 \cdot 0.39)=0.23 \cdot 10^{-5}
\end{aligned}
$$




$$
P\left(S_{5}\right) P\left(K^{*} / S_{5}\right)=0.05(0.80 \cdot 0.60 \cdot 0.40 \cdot 0.20 \cdot 0.60 \cdot 0.60 \cdot 0.60 \cdot 0.80 \cdot 0.80)=2.65 \cdot 10^{-5} .
$$

As noted above, the denominator of the generalized Bayes' formula is the same for all states, and will be obtained by next formula:

$$
\sum P(S) P\left(K^{*} / S\right)=(0+0+0.02+0.23+2.65) \cdot 10^{-5}=2.9 \cdot 10^{-5} .
$$

Then the a posteriori state probabilities for beams $G_{l}$ :

$$
\begin{aligned}
& P\left(G_{11} / K_{1}^{*}\right)=0 / 2.9=0 ; P\left(G_{12} / K_{1}^{*}\right)=0 / 2.9=0 \\
& P\left(G_{13} / K_{1}^{*}\right)=0.02 / 2.9=0.0068 ; P\left(G_{14} / K_{1}^{*}\right)=0.23 / 2.9=0.079 \\
& P\left(G_{15} / K_{1}^{*}\right)=2.65 / 2.9=0.913
\end{aligned}
$$

Given decision rule above, the diagnosed beam $\boldsymbol{G}_{\boldsymbol{1}}$ throughout the combination of technical state.

\section{Results and Discussion}

In this article were discussed two variants of state related to considered elements of building:

1. In first option, calculation results didn't lead to high-quality change distribution picture of states probabilities. It was noticedinbothcase of the most negative manifestation of signs, and in case most favorable.

2. In second option, results of calculation, in some cases, shows high-quality transition to new state compared with initial state, this transition was noticedinbothcases, when settlement picture of probabilitiesdistribution was deteriorated, and when its improvement takes place.

Condition of any building element can be estimated by various diagnostic signs [9] The authors have analyzed diagnostic matrix for the fifteen options of beams state in monolithic concrete reinforced overlap $\left(G_{1}, G_{2}, \ldots, G_{15}\right)$. As calculation results were outcome the values of posteriori (estimated) probabilities for five technical conditions, the largest of which says about assignment to appropriate state. Technical states are presented by five categories [9]: 1 - serviceable, 2 - usable, 3 - limited-usable, 4 - unacceptable, 5 emergency.

Obtained posterior probabilities for the five states of the beam by different implementations of diagnostic features. You could see results of calculation in the tables below. In these tables, the first column is the initial state of the beam, which is obtained by calculation, without exception signs. The next columns show the results obtained by the sequence of their exclusion.

In most cases, the qualitative picture almost remained unchanged when comparison was from initial state, when the diagnosis includes all the features, to state obtained the exclusion of a particular sign.

The article presents the most vivid realization, by which one can assess the stability of the matrix. In other realization signs picture practically didn't change therefore author think it is unnecessary to give results for all considered cases. Examples are given below in paragraphs 1.1, 1.2, 2.1 and 2.2

1.1. In this example considered realization of signs in which all positive categories are excluded from consideration. Results demonstrate that the beam will accept the worst state 
- emergency $\left(S_{5}\right)$.It should be noted that this category says that exploitation of overlap is impossible. Therefore, the identification of this category is essential for research practices. This also applies to the previous category - unacceptable $\left(S_{4}\right)$.

Table 2. Posteriori probabilities of beam G1.

\begin{tabular}{|c|c|c|c|c|c|c|c|c|c|c|}
\hline 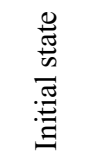 & 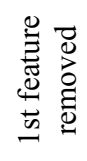 & 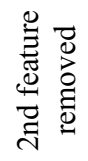 & 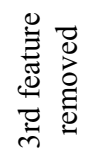 & 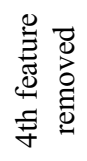 & 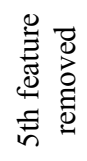 & 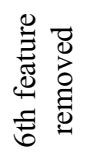 & 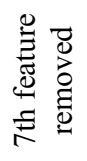 & 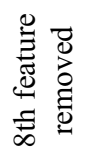 & 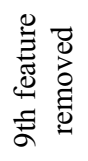 & 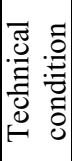 \\
\hline 0.000 & 0.000 & 0.000 & 0.000 & 0.000 & 0.000 & 0.000 & 0.000 & 0.000 & 0.000 & S1 \\
\hline 0.005 & 0.001 & 0.002 & 0.021 & 0.004 & 0.011 & 0.014 & 0.015 & 0.020 & 0.018 & S2 \\
\hline 0.147 & 0.048 & 0.079 & 0.274 & 0.172 & 0.245 & 0.228 & 0.261 & 0.463 & 0.240 & S3 \\
\hline 0.057 & 0.029 & 0.103 & 0.079 & 0.064 & 0.064 & 0.066 & 0.115 & 0.082 & 0.096 & S4 \\
\hline 0.791 & 0.921 & 0.816 & 0.626 & 0.760 & 0.679 & 0.693 & 0.608 & 0.435 & 0.646 & S5 \\
\hline
\end{tabular}

1.2. The realization of diagnostic features, when the element receives a steady third limited-usable $\left(S_{3}\right)$ technical condition. The highest value of probability of these states indicates the appointment of categories state. Evidently, by results of considered signs realization, in all cases the third state is obtained, despite little changes of numerical values of probabilities, despite an exception of signs. Based on this, we can conclude that the qualitative picture is saved and diagnostic matrix demonstrates itself as a stable probabilistic model of beam state.

1. Realizations of signs for $\mathrm{G} 2$ beam:

2. there are not damages of external surface;

3. there are longitudinal cracks in protective layer;

4. there are normal cracks with width of opening less than $0,4 \mathrm{~mm}$;

5. there are inclined cracks;

6. strength of concrete is the same as design strength;

7. corrosion of naked armature is fewer than $5 \%$;

8. deflection exceeds limit by more than $30 \%$;

9. strength condition according the calculation by normal cross-section is not satisfied;

10. strength condition according the calculation by inclined sections is satisfied.

Table 3. Posteriori probabilities of beamG2.

\begin{tabular}{|l|l|l|l|l|l|l|l|l|l|}
\hline 0.021 & 0.016 & 0.067 & 0.011 & 0.084 & 0.012 & 0.009 & 0.069 & 0.044 & 0.014 \\
\hline 0.285 & 0.233 & 0.393 & 0.191 & 0.406 & 0.252 & 0.155 & 0.405 & 0.365 & 0.214 \\
\hline 0.617 & 0.591 & 0.519 & 0.610 & 0.440 & 0.535 & 0.684 & 0.472 & 0.565 & 0.643 \\
\hline 0.054 & 0.079 & 0.013 & 0.141 & 0.042 & 0.152 & 0.115 & 0.046 & 0.022 & 0.055 \\
\hline 0.024 & 0.080 & 0.008 & 0.047 & 0.029 & 0.050 & 0.038 & 0.008 & 0.004 & 0.074 \\
\hline
\end{tabular}

2.1. The probability distribution shows that the condition is within the range from 3 to 4 states. This is due to the fact that the highest probability is distributed between two states.

When excluding the most significant positive traits $(4,7$, and 8$)$ beam falls in a bad state, as it is required to prove in this article. The probability distribution shows that the condition is getting worse, when positive categories of signs did not taken into account. Also obtained that the entropy increases and the system becomes less certain. 
Realizations of signs for $G_{3}$ beam:

1. there are not damages of external surface;

2. there are not longitudinal cracks in protective layer;

3. there are normal cracks with width of opening less than $0.4 \mathrm{~mm}$;

4. there are not inclined cracks;

5. strength of concrete is the same as design strength;

6. corrosion of naked armature is fewer than $5 \%$;

7. deflection does not exceeds limit;

8. strength condition according the calculation by normal cross-section is satisfied;

9. strength condition according the calculation by inclined sections is not satisfied.

Table 4. Posteriori probabilities of beam G3.

\begin{tabular}{|l|l|l|l|l|l|l|l|l|l|}
\hline 0.012 & 0.033 & 0.053 & 0.004 & 0.055 & 0.014 & 0.023 & 0.006 & 0.010 & 0.008 \\
\hline 0.140 & 0.253 & 0.268 & 0.060 & 0.227 & 0.118 & 0.201 & 0.119 & 0.122 & 0.106 \\
\hline 0.468 & 0.497 & 0.546 & 0.296 & 0.380 & 0.612 & 0.437 & 0.374 & 0.428 & 0.490 \\
\hline 0.378 & 0.215 & 0.132 & 0.637 & 0.336 & 0.253 & 0.335 & 0.497 & 0.431 & 0.389 \\
\hline 0.002 & 0.001 & 0.001 & 0.003 & 0.003 & 0.003 & 0.004 & 0.005 & 0.009 & 0.007 \\
\hline
\end{tabular}

2.2. Compares two cases, first, where all the signs according to the initial state, the second where one of the features excluded. In case of exception of the fourth sign (presence of inclined cracks) and the seventh (deflection size), there is a qualitative change to more favorable technical state. The highest values of probability occur in the first three states.

Realizations of signs for $G_{4}$ beam:

10. there are not damage so external surface;

11. there are not longitudinal cracks in protective layer;

12. there are normal cracks with width of opening less than $0.4 \mathrm{~mm}$;

13. there are inclined cracks;

14. strength of concrete is the same as design strength;

15. corrosion of naked armature is fewer than $5 \%$;

16. deflection does not exceeds limit;

17. strength condition according the calculation by normal cross-section is satisfied;

18. strength condition according the calculation by inclined sections is not satisfied.

Table 5. Posteriori probabilities of beam G4.

\begin{tabular}{|l|l|l|l|l|l|l|l|l|l|}
\hline 0.140 & 0.121 & 0.122 & 0.089 & 0.397 & 0.099 & 0.072 & 0.089 & 0.131 & 0.413 \\
\hline 0.343 & 0.318 & 0.327 & 0.282 & 0.344 & 0.363 & 0.228 & 0.377 & 0.337 & 0.358 \\
\hline 0.516 & 0.559 & 0.548 & 0.625 & 0.258 & 0.535 & 0.697 & 0.533 & 0.530 & 0.229 \\
\hline 0.001 & 0.002 & 0.003 & 0.003 & 0.001 & 0.003 & 0.002 & 0.002 & 0.001 & 0.000 \\
\hline 0.000 & 0.001 & 0.000 & 0.000 & 0.000 & 0.000 & 0.000 & 0.000 & 0.001 & 0.000 \\
\hline
\end{tabular}

\section{Summary}

In most considered cases it wasn't noted high-quality transition from one state to another in comparison with initial realization. Where was observed only quantitative changes between posteriori probabilities of the states. It shows the stability and informative of statistical data, which form the basis for creating diagnostic matrices, as well as the basis for constructing a multi-level procedure of diagnosing the state of overlap and buildings in general. 


\section{References}

1. V.A. Sokolov, Civil Engineering magazine, 4(14), 49-58 (2010)

2. V.A. Sokolov, Journal of Civil Engineering, 7(25), 45-51 (2011)

3. S.H. Shakov, F.E. Kovalev, V.M. Vaskevich, V.Y. Ryzhikov, Civil Engineering Journal, 7(33), 76-88 (2012)

4. O.N. Popova, T.L. Simankina, Civil Engineering Journal, 7(42),40-50 (2013)

5. T.N. Soldatenko, Civil Engineering Journal, 7, 52-61 (2011)

6. GOST R 53778-2010 Rule of inspection and condition monitoring

7. GOST 31937-2011. Buildings and constructions. Rule of inspection and condition monitoring

8. V.A. Sokolov, Civil Engineering Journal, 5(15), 31-37 (2010)

9. V.A. Sokolov, Civil Engineering Journal, 3(13), 27-31 (2010)

10. V.A. Sokolov, Civil Engineering Journal, 2(12), 3 (2010)

11. I.A. Birger, Technical Diagnostics Engineering (1978)

12. SP 13-102-2003. Terms surveys bearing structures of buildings and structures. Code of practice for design and construction (2003).

13. A.S. Zolotov, Civil Engineering Journal, 1(27), 14-21 (2012)

14. S.N. Savin, S.V. Demishin, I.V. Sitnikov, Civil Engineering Journal, 7(25), 33-39 (2011)

15. G.L. Koziniec, Civil Engineering Journal, 5(23), 43-48 (2011)

16. A.V. Perelmuter, S.F Pichugin, Magazine of Civil Engineering, 5(49), 5-14 (2014)

17. I.S. Ptuhina, M.E. Viatkin, T.A. Musorina, Construction of Unique Buildings and Structures, 9(14), 46-56 (2013)

18. J. Tamošaitienèa, E. Gaudutisb, M. Kračkaa, Procedia Engineering, 1151-1155 (2013)

19. B. Kovačič, R.Kamnik, M.Premrov, Survey Review, 230, 150-161 (2011)

20. B.Kovačič, R. Kamnik, Geodetski List, 63(4), 315-327 (2009)

21. O.N. Popova, T.L. Simankina, Magazine of Civil Engineering, 7(42), 40-50 (2013)

22. B. Kovačič, Z. Kapović, M. Premrov, A. Breznikar, International Journal for Engineering Modelling, 13(3-4), 85-91 (2000) 